\title{
Effectiveness of psycho-education on depression, hopelessness, suicidality, anxiety and substance use among basic diploma students at Kenya Medical Training College
}

\author{
${ }^{1}$ Kenya Medical Training College and Daystar University, Nairobi, Kenya \\ ${ }^{2}$ Department of Psychiatry, University of Nairobi, Kenya \\ ${ }^{3}$ Africa Mental Health Foundation, Nairobi, Kenya
}

S K Muriungi, ${ }^{1}$ Msc, PhD (Clinical Psychology); D M Ndetei, ${ }^{2,3}$ MB ChB, DPM, MRC Psych, FRC Psych, MD

Corresponding author: S K Muriungi (skagwi2004@yahoo.com)

\begin{abstract}
Objective. To determine the effectiveness of psycho-education on symptom severity in depression, hopelessness, suicidality, anxiety and risk of substance abuse among para-medical students at Kenya Medical Training College (KMTC).

Methodology. A clinical trial drew experimental ( $N=1181)$ and control $(N=1926)$ groups from different KMTC campuses. Self-administered questionnaires were used to collect data: the researcher-designed social demographic questionnaire was used at baseline only, while Beck's Depression Inventory, Beck's Hopelessness Scale, Beck's Suicide Ideation Scale, Beck's Anxiety Inventory and World Health Organization alcohol, smoking and substance involvement screening test (ASSIST) (for drug abuse) were used for baseline, mid-point and end-point assessments at 3-month intervals. The experimental group received a total of 16 hours of structured psycho-education. All study participants gave informed consent.

Results. Overall, there was no significant reduction in symptom severity between the experimental and control groups at 3 months $(p>0.05)$ but there was a significant difference at 6 months $(p<0.05)$.

Conclusion. Psycho-education was effective in reducing the severity of symptoms of depression, hopelessness, suicidality, anxiety and risk of substance abuse at 6 months.
\end{abstract}

S Afr J Psych 2013;19(2):41-50. DOI:10.7196/SAJP.401

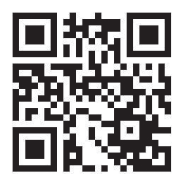

Substantial evidence supports the use of psychological therapies - particularly cognitive behavioural therapy (CBT) - through various methods of psycho-education in the prevention or treatment of mild to moderate depression, anxiety, moderate substance abuse and consequently, hopelessness and suicidality. ${ }^{[1]}$ Researchers have devised several components of psycho-education geared towards symptom recognition and stress-coping skills, among other things, which mental health professionals have found to be effective in preventing and reducing the symptoms of these conditions.

Psycho-education has also been found to promote self-referral to healthcare providers, by enhancing symptom recognition and reducing stigma. ${ }^{[2,3]}$ An individual's ability to understand the effects of psycho-stressors as risk factors can help reduce these conditions' prevalence among patients or the general population, and individuals equipped with appropriate stress-coping strategies can deal with possible psycho-stressors before they become chronic. ${ }^{[2]}$

The most common mental disorders diagnosed in primary-care settings are depression, anxiety and substance-related disorders, which can be present alone or comorbid with another mental disorder. ${ }^{[4]}$ Hopelessness and suicidality are symptoms in a number of mental disorders, such as depression, schizophrenia, anxiety or substance abuse. $^{[5-7]}$ Common in the general population, these debilitating conditions affect general well-being, functioning, productivity and quality of life if left unmanaged, making it hard to do everyday tasks completely, competently and efficiently. ${ }^{[8-11]}$

These conditions also have a psychosocial component that is closely related to negative social relationships, environmental challenges or an individual's inadequate ability to cope effectively with stress. These challenges have been found to be predominant among medical students. ${ }^{[12-15]}$ Because the diagnosis of depression, anxiety, hopelessness or suicidality by general practitioners is often poor, the proportion of sufferers who receive treatment is low.

Among students entering the health professions, these conditions not only affect their lives negatively but may also have repercussions for patient care in the long run. ${ }^{[10,14]}$ Rosenthal and Okie ${ }^{[5]}$ noted that medical students are more prone to depression than their nonmedical peers. This could be because medical students constantly encounter very sick patients or even deaths among their patients. Psycho-education in recognising the symptoms of these conditions and understanding their causes, as well as skills for coping with stress, may facilitate their prevention, and possibly control of their occurrence.

In a study involving 1st- and 2nd-year medical students in a Californian University, aimed at investigating the use of mental health services and its barriers, Givens et al. found that about a quarter of 
the respondents were depressed. ${ }^{[15]}$ Noting the increased prevalence of these conditions in these students compared with their non-medical peers, the study noted a negative attitude towards mental illness among the respondents and therefore an unwillingness to openly seek help.

Givens et al ${ }^{[15]}$ also found that the students had poor coping strategies for the stresses of school life, which included inadequate sleep hours, reduced social life, fatigue and academic challenges.As medical students encounter serious illness and deaths within their practical learning sessions, their emotional balance may be compromised, leaving them vulnerable to anxiety, depression and substance abuse.

\section{Psycho-educational interventions}

Various interventions have been employed to prevent or manage mental disorders. Psycho-education is a cost-effective interventional approach that emphasises teaching stress-coping strategies such as goal setting, skills teaching, satisfactory goal achievement, assertiveness and communication skills. These help to mitigate the development of depression or anxiety. ${ }^{[16-18]}$

According to Colom and Lam, ${ }^{[16]}$ psycho-education focuses on the early identification of prodromal signs and possible predisposing and precipitating causes of these mental disorders. Patients' understanding of their conditions will facilitate compliance and encourage them to seek appropriate management. It also encourages individuals to explore their health beliefs and illness awareness, and enables them to understand the complex relationship between symptoms, personality, interpersonal factors and environment.

Over a 9-month period, Christensen et al. ${ }^{[17]}$ offered CBT through computerised or telephone channels to 301 clients diagnosed with depression and anxiety, and who were receiving pharmacotherapy. They found a significantly beneficial effect over 24 months.

A comparative randomised trialby MacKinnon et al. ${ }^{[18]}$ used online CBT (consisting of 5 interactive modules on cognitive restructuring, pleasant activities and assertiveness training, problem solving and relaxation sessions), which was provided through the information website for depression in the United States. The study found significant benefits in symptom reduction among the experimental group. Their initial mean on the Center for Epidemiologic Studies depression scale (CES-D) was 21.8, which fell to 15.6 after 6 months and 14.1 after 12 months. In comparison, the control group's was 21.6 , which fell to 17.8 after 6 months and 16.4 after 12 months.

No similar studies have studied the effects of psycho-education among college students or any other category of respondents in Kenya. This study aimed to fill this knowledge gap, while contributing to the global data.

\section{Methods}

The study aimed to determine the effectiveness of psycho-education on depression, hopelessness, suicidality, anxiety and risk of substance abuse among first- and second-year basic diploma students. Three assessments of both groups were carried out at 3-month intervals to determine the effectiveness of the psycho-education given to the experimental group.

\section{Study population}

The current study was a clinical trial involving an experimental $(N=1181)$ and control ( $N=1926)$ group drawn from 7 campuses of
Kenya Medical Training College (KMTC). The Nairobi campus the constituted experimental group and the Nakuru, Port Reize, Mombasa, Kisumu, Muranga and Meru campuses constituted the control group. Students were pursuing any of the courses offered at basic diploma level: nursing, medical records and information sciences, community oral health, laboratory sciences, public health sciences, medical imaging sciences, neurophysiology, clinical medicine, dental technology, occupational therapy, optometry, orthopaedic technology, physiotherapy, pharmacy and medical engineering sciences.

This was a cross-sectional study. All students from the campuses who gave informed consent were recruited. Exclusion criteria included undertaking a post-basic course or not giving consent.

\section{Data collection instruments}

The research instruments were 6 self-administered questionnaires:

- A researcher-designed questionnaire for socio-demographic characteristics (SDQ): gender, age, year of study, marital status, place of residence while studying, religion and campus location.

- The Beck's Depression Inventory (BDI), ${ }^{[19]}$ a 21 -item self-report inventory which measures the severity of depression in a general population. This widely used instrument discriminates subtypes of depression, differentiates depression from non-depressed patients has a high coefficient alpha of $0.93(p=0.001)$ for college students, and a validity and reliability of $90 \%$. The BDI cut-off points used in this study were: 0 - 9 for minimal depression, $10-18$ for mild depression, 19 - 29 for moderate depression and $30-63$ for severe depression.

- The Beck's Hopelessness Scale (BHS) ${ }^{[20,21]}$ is designed to reflect the respondent's negative expectancies in various psychopathological conditions. This scale has been administered in diverse samples of patients and among the general population to assess its psychometric properties, and has been found to have a high degree of internal consistency. It also shows a relatively high correlation with the clinical ratings of hopelessness and other self-administered measures of hopelessness. Scores provide a measure of the severity of reported hopelessness: 0 - 3 for minimal, 4 - 8 for mild, 9 - 14 for moderate and 15 - 20 for severe.

- The Beck's Suicide Ideation Scale (BSIS) ${ }^{[21]}$ measures the severity of risk of suicidality and constitutes a 21 -item self-report questionnaire. The instrument identifies those respondents with passive or active suicidal ideas, those with low, moderate or severe suicidal plans and those who have attempted suicide. ${ }^{[16]}$

- The Beck's Anxiety Inventory (BAI) ${ }^{[22]}$ is a 21 -question instrument designed to measure the severity of anxiety in a general population. It shows proven high interval consistency and test/re-test reliability over 1 week. In the general population, respondents must score $\geq 36$ to be considered to have anxiety. The BDI and BAI have been validated against the Diagnostic and Statistical Manual of Mental Disorders (Fourth Edition) (DSM-IV) respective diagnostic criteria in the western countries, where they have been used extensively for similar and other relevant surveys. ${ }^{[19,22]}$ The cut-off points for the BAI used for this study were: 0 - 7 for minimal, 8 - 15 for mild, 16 25 for moderate and 26 - 63 for severe anxiety.

- The World Health Organization (WHO) alcohol, smoking and substance involvement screening test (ASSIST). ${ }^{[23]}$ The National Institute of Drug Abuse (NIDA) has adopted the WHO ASSIST 
version 6, used among the general population, which investigates the risk of psychoactive substance use/abuse in individuals who use a number of substances and exhibit substance use of a minimal, mild, moderate or severe degree. ${ }^{[24]}$ The scores of all the other substances - including alcohol, tobacco, cannabis, cocaine, amphetamines, inhalants, sedatives, hallucinogens, opioids and others - are given. ${ }^{[24]}$ The cut-off points for ASSIST were, (i) for alchohol: lower risk 0 - 10, moderate risk $11-26$, high risk $\geq 27$; (ii) for all other substances: lower risk 0 - 3 , moderate risk 4 - 26 , high risk $\geq 27$.

All 6 instruments were self-administered and took an average of 1.5 hours to complete.

\section{Intervention}

All participants gave informed consent and confidentiality was maintained throughout the study. All respondents in both groups were advised that if they recognised the symptoms/conditions being investigated, they were free to make self-referrals. All respondents were given information on resources available for help.

In the experimental group, baseline characteristics were obtained. This was followed by 4 psycho-education sessions. These 2-hour sessions comprised lectures, simulations, group discussions and role-plays. They incorporated predisposing/precipitating causes of depression, hopelessness, suicidality, anxiety and substance abuse, as well as symptom recognition and stress-coping skills/ strategies. Reassessment was carried out 3 months after the initial intervention to investigate its effects, followed immediately by another 8 hours of psycho-education in 2-hour sessions. A final reassessment was carried out 3 months after the second assessment (6 months after the baseline assessment). All participants were free to contact the principal investigator if they felt that they had a psychological problem or related to the symptoms featured in the questionnaires.

In the control group, no interventions were provided. (However, respondents were free to self-refer to a healthcare provider. Reassessment was done at 3 and 6 months. Participants were provided with a 24-hour helpline in case they developed suicidal tendencies or needed help of any kind.

\section{Psycho-education intervention and reassessments}

The initial 4 sessions of psycho-education given to the experimental group included a 2-hour session on definitions of terms, causes of the conditions and symptom recognition. Another 2 sessions involved theoretical lectures and simulations on stress-coping strategies/skills. These included scheduling/time management, communication skills, decision-making techniques, problem solving, assertiveness training, improving self esteem, sleep hygiene, breathing techniques, controlled breathing/de-arousal, anger-management techniques, relaxation exercises, progressive muscle relaxation, general exercise activities and adherence training. A clinical psychologist supervised small group discussions.

After 3 months, assessment was followed immediately by a repeat of the same process of psycho-education, in addition to addressing the challenges that the respondents had experienced after the first round.

Each psycho-education programme in all the departments in the experimental group lasted between 1.5 months and 2 months.

\section{Data management}

The collected data were double-entered by 2 separate groups of data-entry clerks, and cleaned and analysed using SPSS (version 16), utilising descriptive and inferential statistics. Results were presented in the form of tables and narratives.

\section{Results}

The socio-demographic characteristics of the study sample across the three assessments are summarised in Table 1.

At assessment 1 (baseline), there was no difference in the prevalence of depression between the control and the experimental groups: minimal $20.6 \%$ v. $20.8 \%$; mild $12.6 \%$ v. $13.1 \%$; moderate $18.4 \%$ v. $20.2 \%$; and severe $48.5 \%$ v. $45.8 \%$ respectively. During assessment 2, 3 months after the first psycho-education session, there was no difference in the prevalence of depression.

At assessment 3, 3 months after assessment 2, there was a reduction in the prevalence of severe and moderate depression in the experimental group compared with the control group: moderate $5.2 \% \mathrm{v} .10 .4 \%$; and severe $3.4 \%$ v. $5.0 \%$, respectively. The reduction in depression severity after psycho-education was significant, $(p<0.0001)$ after 6 months.

There was no difference in the prevalence of hopelessness at assessment 1 between the groups. At assessment 2, there was a significant difference $(p<0.0001)$ : moderate depression $3.2 \%$ v. $8.6 \%$ in the experimental and control groups, respectively. The difference was also significant at assessment $3(p=0.001)$.

There was no difference between the groups with regards to suicidality ideas, passive or active, at all the assessments $(p=0.830$, $p=0.288, p=0.059$, chronologically). However, there was a difference in the prevalence reduction rate which was not significant. At assessment 1, passive suicide ideation was $98.3 \%$ v. $99.0 \%$, at assessment 2 was $99.7 \%$ v. $99.8 \%$ and at assessment 3 was $99.2 \%$ v. $98.4 \%$ in the experimental and control groups, respectively. Respectively, the prevalence of active suicidality ideas was $1.7 \% \mathrm{v} .1 .0 \%$ at assessment 1 , $0.3 \%$ v. $0.2 \%$ at assessment 2 and $0.8 \%$ v. $1.6 \%$ at assessment 3 .

At assessment 1, there was a significant difference between the groups in relation to suicidal plan $(p=0.005)$ and suicidal attempts $(p<0.0001)$ (Table 2). However, after 6 months of psycho-education there was no difference between the groups ( $p=0.146$ and $p=0.615$, respectively).

At assessment 1 and 2, there was no difference in the percentage prevalence of anxiety in the 2 groups (Table 2). However, after months of psycho-education, there was a difference in reduction rates of anxiety prevalence between the 2 groups. Moderate anxiety was more prevalent in the experimental group at $14.1 \%$, compared with the control (10.5\%). Severe anxiety was more prevalent in the control group at $7.8 \%$, compared with the experimental group (at 5.4\%). Overall, the difference in the severity of anxiety in the groups was significant after 6 months of psycho-education $(p<0.0001)$ (Table 2).

\section{Risk of alcohol and drug abuse}

At baseline, there was a significant difference in the risk for alcohol abuse between the 2 groups ( $p=0.016$ ), with no difference in the risk of abuse of tobacco, cannabis, cocaine, amphetamine, inhalants, sedatives, opioids and hallucinogens. After 6 months of psychoeducation, there was no significant difference in risk except for cocaine $(p=0.034)$ and cannabis $(p=0.026)$ (Table 3$)$.

Analysis showed that more respondents in the experimental group had self-referred to a mental health facility/professional by the 


\section{Ary

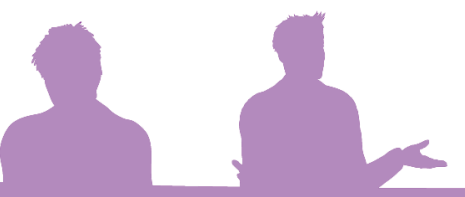 $A<$

Table 1. Socio-demographic background characteristics of the study population

\begin{tabular}{|c|c|c|c|c|c|c|}
\hline & \multicolumn{2}{|c|}{ Assessment 1} & \multicolumn{2}{|c|}{ Assessment 2} & \multicolumn{2}{|c|}{ Assessment 3} \\
\hline & $\begin{array}{l}\text { Experimental } \\
(n=1181)\end{array}$ & $\begin{array}{l}\text { Control } \\
(n=1926)\end{array}$ & $\begin{array}{l}\text { Experimental } \\
(n=1156)\end{array}$ & $\begin{array}{l}\text { Control } \\
(n=1741)\end{array}$ & $\begin{array}{l}\text { Experimental } \\
(n=959)\end{array}$ & $\begin{array}{l}\text { Control } \\
(n=1493)\end{array}$ \\
\hline \multicolumn{7}{|l|}{ Gender, \% } \\
\hline Male & 59.3 & 47.4 & 56.9 & 49.9 & 55.9 & 49.0 \\
\hline Female & 40.7 & 52.6 & 43.1 & 50.1 & 44.1 & 51.0 \\
\hline \multicolumn{7}{|l|}{ Age group, \% } \\
\hline$<25$ years & 90.3 & 91.6 & 92.4 & 92.7 & 88.8 & 88.6 \\
\hline$>25$ years & 9.7 & 8.4 & 7.6 & 7.3 & 11.3 & 11.4 \\
\hline \multicolumn{7}{|l|}{ Year of study, \% } \\
\hline 1 st & 50.6 & 63.3 & 53.4 & 59.4 & 63.0 & 59.5 \\
\hline 2nd & 49.4 & 36.7 & 46.6 & 40.6 & 37.0 & 40.5 \\
\hline \multicolumn{7}{|l|}{ Place of residence, $\%$} \\
\hline Within college hostels & 81.1 & 82.4 & 80.9 & 71.5 & 80.7 & 74.4 \\
\hline Outside college hostels & 18.9 & 17.6 & 19.1 & 28.5 & 19.3 & 25.6 \\
\hline \multicolumn{7}{|l|}{ Marital status, \% } \\
\hline Single & 94.5 & 94.4 & 94.1 & 95.6 & 94.7 & 94.2 \\
\hline Married & 4.6 & 5.2 & 5.7 & 4.0 & 4.8 & 4.9 \\
\hline Separated/divorced/widowed/other & 0.5 & 0.5 & 0.3 & 0.4 & 0.5 & 0.9 \\
\hline \multicolumn{7}{|l|}{ Religion, \% } \\
\hline Protestant & 65.4 & 60.7 & 66.4 & 60.6 & 66.7 & 62.6 \\
\hline Catholic & 27.8 & 28.6 & 27.7 & 30.2 & 26.9 & 29.9 \\
\hline Muslim & 2.9 & 5.7 & 2.7 & 4.6 & 2.5 & 4.0 \\
\hline Other & 3.8 & 5.0 & 3.2 & 4.6 & 3.9 & 3.5 \\
\hline
\end{tabular}

second and third assessment ( $n=200 \mathrm{v} . n=239$, respectively) than in the control group ( $n=144$ v. $n=137$, respectively). The self-referral means were higher in the experimental group than the control group in the second ( 0.1787 v. 0.2495 , respectively) and third assessments ( 0.0919 v. 0.0835 , respectively). ANOVA testing showed a statistically significant difference between the means in the 2 study groups in assessments 2 and 3 ( $p=0.001$ and $p<0.0001$, respectively).

Analysis of variance was used to test for differences in the means of the prevalence of conditions between the 2 groups in the 3 assessments, to show the effects on outcomes of the intervention used. Analysis of the means of depression, hopelessness, suicidality, anxiety and the risk of substance abuse showed progressive reduction of means across the assessments between the 2 study groups, with a greater reduction among the experimental group in the third assessment (Table 4). In assessment 1, the conditions which showed significant differences between the 2 groups were suicidal attempts, anxiety, tobacco and sedatives. In assessment 2, only hopelessness had a significant difference (Table 5) while in assessment 3, depression, hopelessness, suicidal ideas, suicidal plans, cannabis and cocaine showed significant differences.

There was significant difference between the means of some conditions in each group, with more effectiveness within the experimental group. Even where differences were not significant, they were larger in the experimental group than in the control group, with the highest difference between the first and third assessments.

\section{Discussion \\ Population studies}

The high return rate was attributed to the fact that, before the data collection period, the researchers had worked to sensitise both the respondents and campus administrators. Previous studies by Ndetei $e t$ al. ${ }^{[12,13]}$ found $100 \%$ response rates in educational institutions.

There were more male than female respondents, which the researchers infer is due to the imbalances between males and females in the various campuses, since there were higher numbers of males in the experimental group. Most respondents were aged $<24$ years and single, having been admitted to KMTC after high school. The majority of students aged $\geq 24$ years, and who were married, separated, divorced or widowed, had come for upgrading from a certificate to a diploma. The researchers inferred that the age difference was due to the high number of first year students, who were more often under 24 than 2nd year students. More than half of the respondents in both groups were protestants which meant there was a skew which contributed to differential representation of the religions in the sociodemographic characteristics of the 2 age groups.

\section{Prevalence of conditions across the assessments}

At assessment 1, there were generally similar overall prevalence levels of all conditions among the experimental and control groups. It was inferred that the factors precipitating the respondents to develop the conditions may have been similar among the 2 study groups, that 


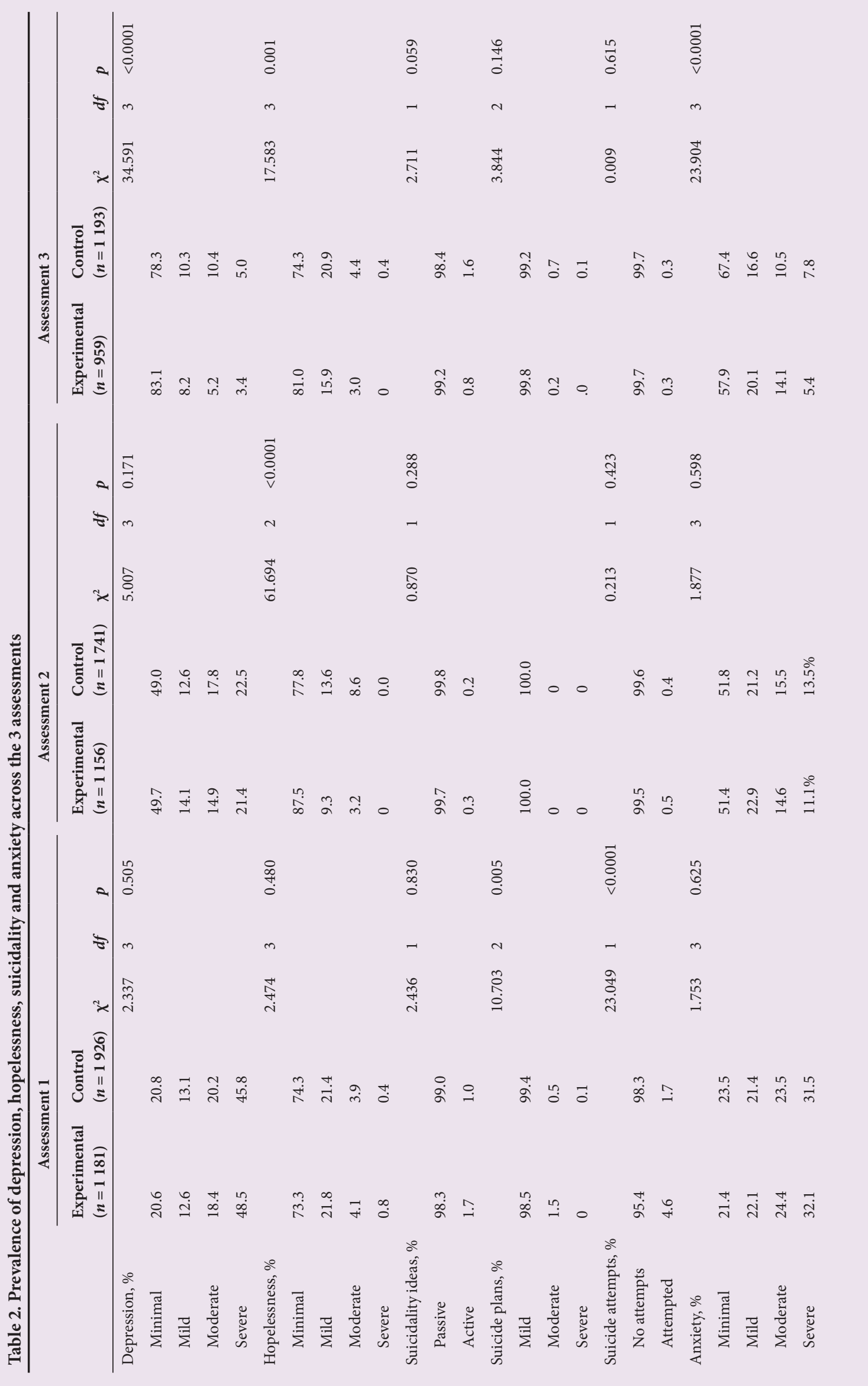




\title{
10,3ra
}

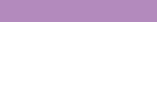

\begin{tabular}{|c|c|c|c|c|c|c|}
\hline$\stackrel{\infty}{\circ}$ & 苋 & 容 & 管 & 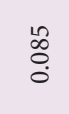 & 节 & 紫 \\
\hline$\sim$ & - & - & - & - & - & - \\
\hline 兽 & 嵩 & 离 & סू & $\begin{array}{l}\text { 菏 } \\
\text {. }\end{array}$ & $\begin{array}{l}\tilde{d} \\
\text { in }\end{array}$ & $\stackrel{\vec{\Phi}}{\vec{\Phi}}$ \\
\hline
\end{tabular}

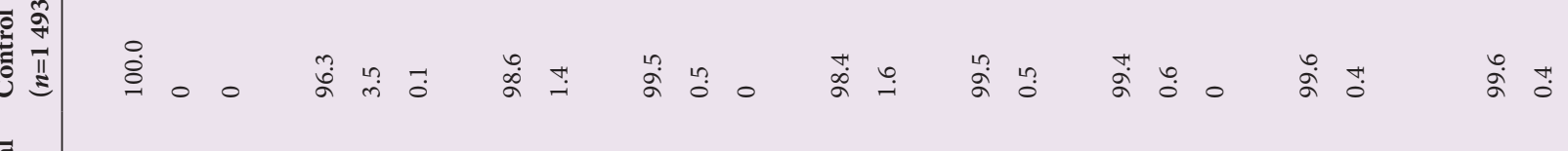

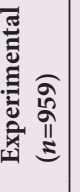

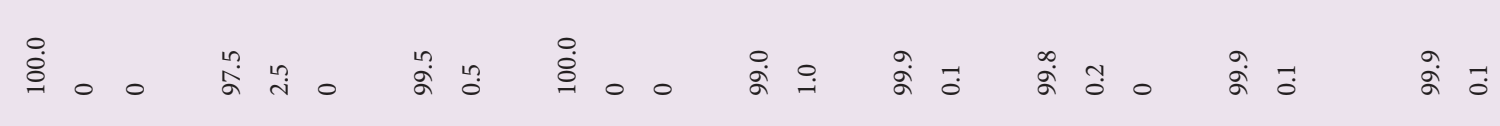

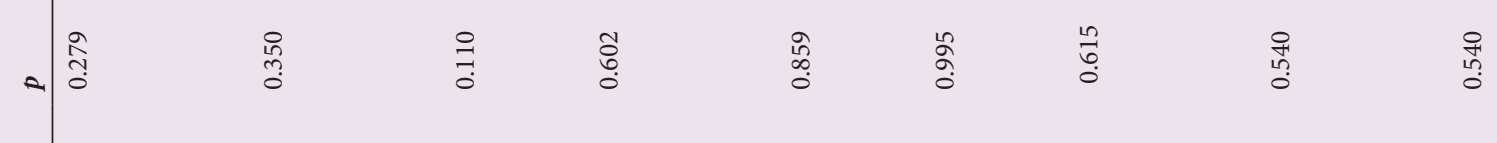
$\exists \sim$
$\approx$ *
वे
ริ

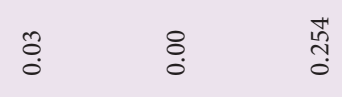
鹿
웅

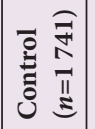

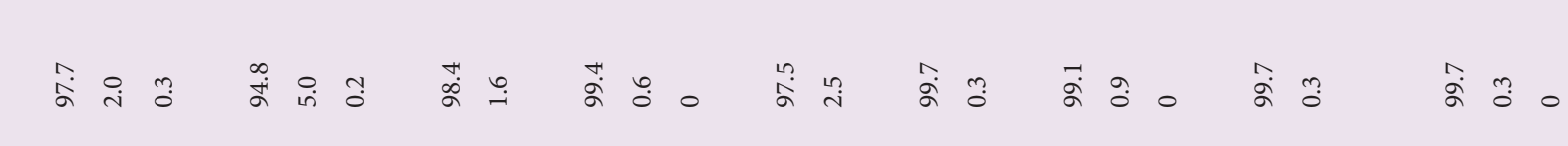

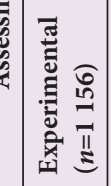
2.

苾 $\stackrel{-}{0}=$

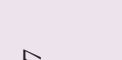

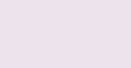

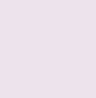


there were certain general risk factors above specific or peculiar campus factors, and that there were risk factors other than academic stressors which predisposed the respondents to psychological morbidity.

The high levels of severe depression and anxiety among respondents in the first assessment could be explained by the stressors facing these students, such as new lifestyles and cultures, new friends and exposure to alternative ways of thinking. As they progressed in their training and adjusted to new lifestyles and social environments, they were required to develop new coping strategies. Those who could not cope effectively were more susceptible to anxiety or depression symptoms, which may have progressed to full-blown conditions and consequently increased hopelessness and suicidality, or to higher risks of substance abuse. ${ }^{[3,25]}$

A similar study investigating the prevalence of depression, anxiety and their associated factors among medical students in Karachi, Pakistan, ${ }^{[26]}$ reported a $70 \%$ rate of anxiety and depression among the respondents. Precipitating causes were not exclusively academic but included loss, relationship problems, residence and substance abuse.

In this study, the prevalence of active suicidal ideations found among both groups in the first assessment can be attributed to the comorbidity of hopelessness among the respondents, or other factors which were not investigated. In the experimental group, the low prevalence of suicidal plans $v$. suicide attempts suggests that those who had attempted suicide may have been influenced by other circumstances than hopelessness, like substance abuse or causes not investigated. It can also be inferred that not all who attempt suicides display prior suicidal ideas or plans.

These results were much lower than the findings of a study of prevalence of suicide ideation among college students, where $43 \%$ had experienced some level of suicidal ideations, $14.9 \%$ had suicidal plans and 5.5\% had made suicide attempts suicide which were attributed to inability to cope with psycho-stressors. ${ }^{[27]}$

The high risk of alcohol abuse in the 2 groups at the first assessment can be explained by alcohol's ready availability and cheapness, making it the substance of choice. The high risk of alcohol abuse was followed closely by the risk of tobacco abuse, amphetamines 
Table 5. Correlation co-efficient test on mean differences of effects of psycho-education between assessment 1 and 2 within each study group

\begin{tabular}{|c|c|c|c|c|c|c|c|c|}
\hline & \multicolumn{4}{|c|}{ Experimental } & \multicolumn{4}{|c|}{ Control } \\
\hline & Assessment 1 & Assessment 2 & F & $p$-value & Assessment 1 & Assessment 2 & F & $p$-value \\
\hline Depression & 2.9475 & 2.1093 & 261.568 & $1.000^{\dagger}$ & 2.9109 & 2.1089 & 385.404 & $0.001^{\dagger}$ \\
\hline Hopelessness & 1.3235 & 1.1566 & 59.626 & $0.001^{\dagger}$ & 1.3037 & 1.3285 & 1.522 & 0.217 \\
\hline Suicidal ideas & 1.0170 & 1.0035 & 10.500 & $0.001^{\dagger}$ & 1.0104 & 1.0017 & 11.113 & $0.001^{\dagger}$ \\
\hline Suicide plans & 1.0152 & 1.0000 & 17.814 & $0.001^{\dagger}$ & 1.0067 & 1.0000 & 9.018 & $0.003^{\dagger}$ \\
\hline Suicide attempts & 1.0457 & 1.0052 & 38.976 & $0.001^{\dagger}$ & 1.0166 & 1.0040 & 13.828 & $0.001^{\dagger}$ \\
\hline Anxiety & 2.6714 & 1.8554 & 317.800 & $0.001^{\dagger}$ & 2.6314 & 1.8760 & 406.002 & $0.001^{\dagger}$ \\
\hline Alcohol & 1.01 & 1.02 & 0.464 & 0.496 & 1.03 & 1.03 & 0.276 & 0.599 \\
\hline Tobacco & 1.07 & 1.05 & 3.385 & 0.056 & 1.06 & 1.05 & 0.168 & 0.682 \\
\hline Cannabis & 1.02 & 1.01 & 2.957 & 0.086 & 1.02 & 1.02 & 0.390 & 0.532 \\
\hline Cocaine & 1.01 & 1.00 & 0.293 & 0.588 & 1.01 & 1.01 & 0.033 & 0.855 \\
\hline Amphetamines & 1.03 & 1.02 & 2.246 & 0.134 & 1.03 & 1.03 & 0.053 & 0.818 \\
\hline Inhalants & 1.01 & 1.00 & 0.360 & 0.549 & 1.00 & 1.00 & 0.120 & 0.729 \\
\hline Sedatives & 1.02 & 1.01 & 7.050 & $0.008^{\ddagger}$ & 1.03 & 1.01 & 24.230 & $0.001^{\dagger}$ \\
\hline Opioids & 1.00 & 1.00 & 1.226 & 0.268 & 1.01 & 1.00 & 1.508 & 0.220 \\
\hline Hallucinogens & 1.00 & 1.00 & 1.226 & 0.268 & 2.9109 & 2.1089 & 1.508 & 0.220 \\
\hline Depression & 2.1093 & 1.3785 & 242.983 & $0.000^{*}$ & 2.1089 & 1.2405 & 613.65 & $0.001^{\dagger}$ \\
\hline Hopelessness & 1.1566 & 1.2231 & 10.744 & $0.001^{\dagger}$ & 1.3285 & 1.3094 & 0.764 & 0.382 \\
\hline \multicolumn{9}{|l|}{ Suicidality } \\
\hline Ideas & 1.0035 & 1.0083 & 2.214 & 0.137 & 1.0017 & 1.0161 & 20.108 & $0.001^{\dagger}$ \\
\hline Plans & 1.0000 & 1.0021 & 2.405 & 0.121 & 1.0000 & 1.0094 & 12.768 & $0.001^{\dagger}$ \\
\hline Attempts & 1.0052 & 1.0031 & 0.526 & 0.469 & 1.0040 & 1.0033 & 0.098 & 0.754 \\
\hline Anxiety & 1.8554 & 1.7182 & 9.560 & $0.001^{\dagger}$ & 1.8760 & 1.5392 & 92.636 & $0.002^{\dagger}$ \\
\hline \multicolumn{9}{|c|}{ Risk of substance abuse } \\
\hline Alcohol & 1.02 & 1.00 & 15.310 & $0.001^{\dagger}$ & 1.03 & 1.00 & 31.936 & $0.001^{\dagger}$ \\
\hline Tobacco & 1.05 & 1.03 & 10.500 & $0.01^{\ddagger}$ & 1.05 & 1.04 & 3.947 & $0.047^{\ddagger}$ \\
\hline Cannabis & 1.01 & 1.01 & 1.292 & 0.256 & 1.02 & 1.01 & 0.114 & 0.735 \\
\hline Cocaine & 1.00 & 1.00 & 4.162 & $0.041^{*}$ & 1.01 & 1.00 & 0.171 & 0.679 \\
\hline Amphetamine & 1.02 & 1.01 & 5.662 & 0.0178 & 1.03 & 1.02 & 3.305 & 0.069 \\
\hline Inhalants & 1.00 & 1.00 & 1.298 & 0.255 & 1.00 & 1.01 & 0.681 & 0.409 \\
\hline Sedatives & 1.01 & 1.00 & 2.605 & 0.107 & 1.01 & 1.01 & 0.730 & 0.393 \\
\hline Opioids & 1.00 & 1.00 & 0.175 & 0.676 & 1.00 & 1.00 & 0.312 & 0.577 \\
\hline Hallucinogens & 1.00 & 1.00 & 0.175 & 0.676 & 1.00 & 1.00 & 0.312 & 0.577 \\
\hline
\end{tabular}

and sedatives. Furthermore, new lifestyles, experiences, financial challenges, psycho-stressors and academic challenges may precipitate involvement in substance abuse. Although Kenya's legal drinking age is 18 years, alcohol and tobacco are readily available even to underage buyers from small-scale, often illicit producers and sellers. ${ }^{[28]}$

A similar study ${ }^{[26]}$ listed reasons for substance use among college students: to relax (62.2\%), to relieve stress $(60.8 \%)$, desire to experiment (41.9\%), peer pressure (38.9\%), and to cope with problems (38.9\%). In another study among Kenyan universities, the prevalence rate of cigarette use was $42.8 \%$, cannabis $2 \%$ and cocaine $0.6 \%{ }^{[29]}$ Among those who admitted to using substances, $75.1 \%$ were introduced to substance use by a friend and $23.5 \%$ were introduced by a relative other than a member of the nuclear family. The majority wanted to relax (62.2\%) or relieve stress $(60.8 \%)$.

\section{Effectiveness of psycho-education interventions}

The prevalence of all the studied conditions and the risk of substance abuse had fallen by assessment 2 and was even lower by assessment 3 
Table 6. Correlation co-efficient test on mean difference of effect of psycho-education between assessments 1 and 3 within each study group

\begin{tabular}{|c|c|c|c|c|c|c|c|c|}
\hline & \multicolumn{4}{|c|}{ Experimental } & \multicolumn{4}{|c|}{ Control } \\
\hline & Assessment 1 & Assessment 3 & F & $p$-value & Assessment 1 & Assessment 3 & F & $p$-value \\
\hline Depression & 2.9475 & 1.3785 & 1186.413 & $0.001^{\dagger}$ & 2.9109 & 1.2405 & 2419.732 & $0.0001^{*}$ \\
\hline Hopelessness & 1.3235 & 1.2231 & 17.769 & $0.001^{\dagger}$ & 1.3037 & 1.3094 & 0.086 & $0.003^{+}$ \\
\hline \multicolumn{9}{|l|}{ Suicidality } \\
\hline Ideas & 1.0170 & 1.0083 & 3.043 & 0.081 & 1.0104 & 1.0161 & 2.093 & 0.148 \\
\hline Plans & 1.0152 & 1.0021 & 9.930 & $0.002^{\dagger}$ & 1.0067 & 1.0094 & 0.570 & 0.450 \\
\hline Attempts & 1.0457 & 1.0031 & 37.655 & $0.001^{\dagger}$ & 1.0166 & 1.0033 & 13.874 & $0.0001^{*}$ \\
\hline Anxiety & 2.6714 & 1.7182 & 413.826 & $0.001^{\dagger}$ & 2.6314 & 1.5392 & 901.014 & $0.0001^{\dagger}$ \\
\hline Alcohol & 1.0100 & 1.0000 & 10.498 & $0.001^{+}$ & 1.0300 & 1.0000 & 38.539 & $0.001^{\dagger}$ \\
\hline Tobacco & 1.0700 & 1.0300 & 23.709 & $0.005^{\ddagger}$ & 1.0600 & 1.0400 & 5.884 & $0.015^{\ddagger}$ \\
\hline Cannabis & 1.0200 & 1.0100 & 6.981 & $0.008^{\ddagger}$ & 1.0200 & 1.0100 & 0.880 & 0.348 \\
\hline Cocaine & 1.0100 & 1.0000 & 5.713 & $0.017^{\ddagger}$ & 1.0100 & 1.0000 & 0.327 & 0.567 \\
\hline Amphetamine & 1.0300 & 1.0100 & 13.493 & $0.0001^{*}$ & 1.0300 & 1.0200 & 4.247 & $0.039^{\ddagger}$ \\
\hline Inhalants & 1.0100 & 1.0000 & 2.647 & 0.104 & 1.0000 & 1.0100 & 0.262 & 0.609 \\
\hline Sedatives & 1.0200 & 1.0000 & 13.939 & $0.0001^{\dagger}$ & 1.0300 & 1.0100 & 27.726 & $0.0001^{*}$ \\
\hline Opioids & 1.0000 & 1.0000 & 1.927 & 0.165 & 1.0100 & 1.0000 & 0.435 & 0.509 \\
\hline Hallucinogens & 1.0000 & 1.0000 & 1.927 & 0.165 & 1.0100 & 1.0000 & 0.435 & 0.509 \\
\hline
\end{tabular}

among both study groups, with higher progressive reduction among the experimental group. This indicates that the psycho-education given to the experimental respondents was effective. The reduction among the control group can be attributed to repeat assessment with the same tools, which may have awakened the respondents to their respective symptoms and inspired them to deal with their conditions. However, the reductions were not consistent. These results are consistent with previous studies. ${ }^{[1,16,30]}$

The higher rate of reduction of all conditions among the experimental respondents across the assessment can be related to the effectiveness of the psycho-education intervention. Experimental respondents were enabled to cope with psycho stressors and the ability to recognise symptoms led them to seek professional help early. The highest effect occurred after the 2 nd psycho-education intervention, 3 months after the 1 st. Outcomes at 6 months were more positive and consistent across the assessments among the experimental respondents, with more respondents self-referring.

A similar study involving 400 patients diagnosed with depression concluded that, if offered to adults, problem solving treatment was effective in reducing cases and improving subjective function. ${ }^{[31]}$ Other studies investigating the effectiveness of psycho-education on various mental disorders have shown similar positive results. ${ }^{[32-36]}$

In the current study, addressing symptom recognition, conditions' predisposing and precipitating causes and comprehensive stresscoping strategies was found effective in cost-effective case reduction.
Other studies have found no significant difference between experimental and control groups if the psycho-education is given by general practitioners ${ }^{[32]}$ while others found no significant difference between experimental and control groups. ${ }^{[37-39]}$

\section{Study limitations}

The study did not investigate whether respondents had suffered depression or anxiety previously, or indentify other possible psychostressors which may have precipitated depression or anxiety. These unknown factors could have contributed to the reduction in the conditions. It is also a limitation that all the participants in the experimental group were recruited from the same site.

Acknowledgements. This work formed part of the requirements of a PhD at the University of Nairobi by SKM. This PhD was supervised by NDM, the lead supervisor, Dr M Mathai (Nairobi University) and Prof. B Sebit (Muhimbili University, Dar Es Salaam, Tanzania). We thank all KMTC student respondents, lecturers and principals who participated in this study; as well as the Director of KMTC, for facilitating the logistics of the study; our professional colleagues J Nga’nga, E Kariuki and V Mutiso for their invaluable assistance during psycho-education; and G Mutevu of Africa Mental Health Foundation for her prompt typographical assistance.

Ethics. The study was approved by the Kenyatta National Hospital/ University of Nairobi ethical and research committee. The Director of the KMTC authorised research on the selected campuses. 


\section{fre
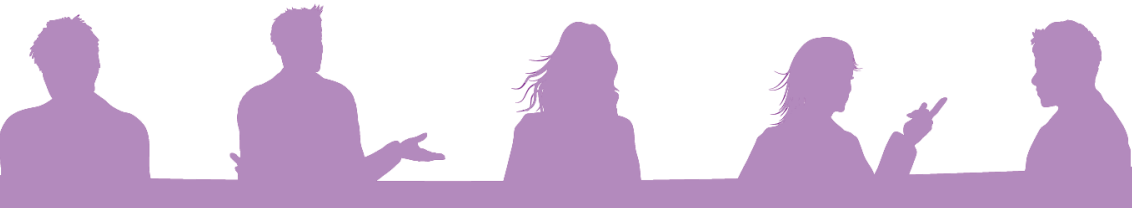 \\ ARTICLE}

\section{References}

1. Kaltenthalar E, Parry G, Beverley C, Ferriter M. Computerized cognitive-behavior therapy for depression: Systematic review. Br J Psychiatry. 2008;193(3):181-184. [http://dx.do org/10.1192/bjp.bp.106.025981]

2. Han DY, Chen SH, Hwang KK, Wei HL. Effects of psycho education for depression on helpseeking willingness: Biological attribution versus destigmatization. Psych Clin Neurosciences 2006;60(6):662-668. [http://dx.doi.org/10.1111/j.1440-1819.2006.01580.x]

3. Oliver JM, Reed C, Smith B. Pattern of psychological problems in university undergraduates: Factor structure of symptoms of anxiety and depression, physical symptoms, alcohol use and eating problems. Soc Behav Personal 1998:26(3):211.

4. Ormel J, VonKorff M, Ustun YB, et al. Common mental disorders and disability across cultures. Results from the WHO Collaborative Study on Psychological Problems in General Health Care. JAMA. 1994;272(22):1741-1748.

5. Rosenthal JM, Okie S. White coat, mood indigo - depression in medical school. N Engl J Med 2005;353(11):1085-1088. [http://dx.doi.org/10.1056/NEJMp058183]

6. Carsons RC, Mineka S, Butcher JN. Abnormal Psychology and Modern Life. Glenview, IL: HarperCollins College Publishers, 1996.

7. Goldberg D, Huxley P. Common Mental disorders: A Biosocial Model. Routledge: London, 1992.

8. Blow FC. Substance abuse among older adults: Treatment improvement protocol (TIP) Series 26. Rockville, MD: US Department of Health and Human Services, 2005.

9. Tjia J, Givens JL, Shea JA. Factors associated with undertreatment of medical student depression. J Am Coll Health 2005;53(5):219-224. [http://dx.doi.org/10.3200/JACH.53.5.219-224]

10. Wells SK, Sherbourne C, Schoenbaum M, et al. Impact of disseminating quality improvement programs for depression in managed primary care: A randomised controlled trial. JAMA 2000;283(2):212-220.

11. Ndetei DM, Khasakhala L, Nyabola L, et al. Prevalence of anxiety and depression symptoms and syndromes in Kenyan children and adolescents. J Child Adolesc Ment Health 2008;20(1):33-51.

12. Ndetei D, Owour F, Ongecha F, et al. Prevalence of mental disorders and the attitudes of staff in general medical facilities. World Health Organization Kenyan report. Geneva: WHO, 2006 .

13. Ndetei DM, Khasakhala L, Mutiso V, et al. Psychosocial and health aspects of drug use by students in public secondary schools in Nairobi Kenya. Subst Abus 2009;30(1):61-68. [http:// dx.doi.org/10.1080/08897070802606410]

14. Barlow DH, Learner JA, Esler JL. Health Psychology Through Lifespan: Practice and Research Opportunities. Washington, DC: American Psychological Association, 1996:133-148.

15. Givens JL, Tjia J. Depressed medical students' use of mental health services and barriers to use Acad Med 2002;77(9):918-921.

16. Colom F, Lam D. Psychoeducation: Improving outcomes in bipolar disorder. Eur Psychiatry 2005;20(5-6):359-364. [http://dx.doi.org/10.1016/j.eurpsy.2005.06.002]

17. Christensen H, Griffiths KM, Mackinnon AJ, et al. Online randomized controlled trial of brief and full cognitive behaviour therapy for depression. Psychol Med 2006;36(12):1737-1746. [http://dx.doi.org/10.1017/S0033291706008695]

18. MacKinnon A, Griffiths KM, Christensen H. Comparative randomised trial of online cognitivebehavioural therapy and an information website for depression: 12-month outcomes. BJP 2008;192(2):130-134. [http://dx.doi.org/10.1192/bjp.bp.106.032078]

19. Beck AT, Steer RA, Carbin MG. Psychometric properties of the Beck Depression Inventory: Twenty-five years of evaluation. Clin Psychol Rev 1988;8(1):77-100. [http://dx.doi. org/10.1016/0272-7358(88)90050-5]

20. Beck AT, Weissman A, Lester D, Trexler L. The measurement of pessimism: The hopelessness scale. J Consult Clin Psychol 1974;42(6):893-897.

21. Beck AT, Thinking and depression I: Idiosyncratic content and cognitive distortions. Arch Gen Psychiatry 1963;9(4):324-333. [http://dx.doi.org/10.1001/archpsyc.1963.01720160014002]
22. Beck AT, Brown G, Steer RA, Eidelson JI, Riskind JH. Differentiating anxiety from depression: A test of the cognitive content-specificity hypothesis. J Abnormal Psychol 1987;96(3):179-183.

23. World Health Organization. The ASSIST project - Alcohol, Smoking and Substance Involvement Screening Test. Geneva: WHO; 1997-2011. http://www.who.int/substance_abuse/ activities/assist/en/ (accessed 28 May 2013).

24. Newcombe DL, Humeniuk RE, Ali R. Validation of the World Health Organization Alcohol, Smoking and Substance Involvement Screening Test (ASSIST): Report of results from the Australian site. Drug Alcohol Rev 2005;24(3):217-226.

25. Morioka H, Nagatomo I, Takigawa M. Alcohol consumption patterns of medical students measured by the Kurihama acoholism screening test. Kagosima: Department of Neuropsychiatry, Faculty of Medicine, Kagosima University; 1999. http://www.jicef.or.jp/ wahec/ful309.htm (accessed 28 May 2013).

26. Khan, MS, Mahood S, Badshah A, et al. Prevalence of depression, anxiety and their associated factors among medical students in Karachi, Pakistan. J Pak Med Assoc 2006;56(12):583-586.

27. Mitchell AJ, Dennis M. Self harm and attempted suicide in adults: 10 practical questions and answers for emergency department staff. Emerg Med J 2006;23(4):251-255. [http://dx.doi. org/10.1136/emj.2005.027250]

28. Partanen J. Failures in alcohol policy: lessons from Russia, Kenya, Truk and history. Addiction 1993;88:129S-134S.

29. Atwoli L, Mungla PA, Ndung'u Mn, Kinoti KC, Ogot EM. Prevalence of substance use among college students in Eldoret, western Kenya. BMC Psychiatry 2011;11:34. [http://dx.doi. org/10.1186/1471-244X-11-34]

30. Baker A, Bucci S, Lewin TJ, et al. Cognitive behaviour therapy for substance use disorders in people with psychotic disorders: Randomised controlled trial. Br J Psychiatry 2006;188:439448. [http://dx.doi.org/10.1192/bjp.188.5.439]

31. Dowrick C, Dunn G, Ayuso-Mateos JL, et al. Problem solving treatment and group psychoeducation for depression:Mmulticentre randomised controlled trial. Outcomes of Depression International Network (ODIN) Group. BMJ 2000;321(7274):1450-1454.

32. Brown JS, Elliott SA, Boardman J, et al Can the effects of a 1-day CBT psychoeducational workshop on self-confidence be maintained after 2 years? A naturalistic study. Depress Anxiety 2008;25(7):632-640. [http://dx.doi.org/10.1002/da.20365]

33. Deas D. Evidence-based treatments for alcohol use disorders in adolescents. Pediatrics 2008;121(4):S348-S354. [http://dx.doi.org/10.1542/peds.2007-2243G]

34. Kaminer Y, Burleson J, Goldberger R. Cognitive-behavioral coping skills and psychoeducation therapies for adolescent substance abuse. J Nerv Ment Dis 2202;190(11):737-745. [http:// dx.doi.org/10.1097/01.NMD.0000038168.51591.B6]

35. Haddock G, Barrowclough C, Tarrier N, et al. Cognitive-behavioural therapy and motivational intervention for schizophrenia and substance misuse. 18-month outcomes of a randomised controlled trial. Br J Psychiatry 2003;183:416-426.

36. Donker T, Griffiths KM, Cuijpers P, Christensen H. Psychoeducation for depression, anxiety and psychological distress: A meta-analysis. BMC Med 2006;16(7):79. [http://dx.doi. org/10.1186/1741-7015-7-79]

37. Huibers MJ, Beurskens AJ, Van Schayck CP, et al. Efficacy of cognitive-behavioural therapy by general practitioners for unexplained fatigue among employees: Randomised controlled trial. Br J Psychiatry 2004;184:240-246.

38. Philip AG, David GF, Daniel F, Paul B, Graham D, Elizabeth K (2008). Cognitive behavior therapy and family intervention for relapse prevention and symptom reduction in psychosis; randomised controlled trial. Br J Psychiatry 192: 412-423.

39. Sumathipala A, Siribaddana S, Abeysingha MRN, et al. Cognitive-behavioural therapy y. structured care for medically unexplained symptoms: randomised controlled trial. $\mathrm{Br}$ J Psychiatry 2008;193(1):51-59. [http://dx.doi.org/10.1192/bjp.bp.107.043190] 